\title{
Towards Low Carbon Business Park Energy Systems: Classification of Techno-Economic Energy Models
}

\author{
Jonas Timmerman*a ${ }^{\mathrm{a}}$, Christof Deckmyn ${ }^{\mathrm{b}}$, Lieven Vandevelde ${ }^{\mathrm{b}}$,Greet Van Eetvelde \\ a Department of Civil Engineering, Ghent University, Vrijdagmarkt 10-301, B-9000, Ghent, Belgium \\ ${ }^{\mathrm{b}}$ Electrical Energy Laboratory (EELAB), Department of Electrical Energy, Systems and Automation (EESA), Ghent University, Sint- \\ Pietersnieuwstraat 41, B-9000, Ghent, Belgium \\ jonas.timmerman@ugent.be \\ Keywords: \\ business park \\ industrial park \\ techno-economic energy model \\ model classification
}

\section{Abstract}

To mitigate climate destabilisation, human-induced greenhouse gas emissions urgently need to be curbed. A major share of these emissions originates from the industry and energy sectors. Hence, a low carbon shift in industrial and business park energy systems is called for. Low carbon business parks minimise energy-related carbon dioxide emissions by maximal exploitation of local renewable energy production, enhanced energy efficiency, and inter-firm heat exchange, combined in a collective energy system. The holistic approach of techno-economic energy models facilitates the design of such systems, while yielding an optimal trade-off between energetic, economic and environmental performances. However, no models custom-tailored for industrial park energy systems are detected in literature. In this paper, existing energy model classifications are scanned for adequate model characteristics and accordingly, a confined number of models are selected and described. Subsequently, a practical typology is proposed, existing of energy system evolution, optimisation, simulation, accounting and integration models, and key model features are compared. Finally, important features for a business park energy model are identified.

\section{Introduction}

Fossil fuel based energy generation in the manufacturing industry and the sector's consumption of externally produced electricity and heat, are responsible for about $25 \%$ of total greenhouse gas emissions on European level [1]. Therefore, a low carbon shift in the energy system of industrial parks must be initiated. Low carbon business parks envision a collective energy system that employs energy efficient technologies, maximises the integration of local renewable energy sources and enables heat exchange between companies [2]. Technoeconomic energy models provide a holistic approach towards the configuration and operation of such systems, and facilitate the optimal trade-off between energetic, economic and environmental performances. To our knowledge, there is no energy model available that has been custom tailored for industrial parks and therefore, the development of such a model by adapting an existing model or by developing a new one is of high priority.

Starting from the viewpoint of low carbon business park energy systems, this paper attempts to unravel the plethora of energy models, proposes a pragmatic model categorisation and identifies key model features. Section 2 describes the configuration of a business park energy system and its components and assesses the need for a holistic modelling approach. In section 3, several existing classifications of techno-economic energy models are screened for appropriate model features and based thereon a new classification is proposed. Its model categories are presented and exemplified throughout sections 4 to 9 . Section 10 provides a clear comparison between these model types per key characteristic. In section 11 , features for efficiently modelling business park energy systems are distilled. Finally, section 13 provides a summary. 


\section{Business park energy system modelling}

\subsection{Business park energy system}

An intuitive general superstructure for business park energy systems is presented in Fig. 1: Energy sources are transformed by energy conversion technologies into forms (heat and electricity) suitable for energy service demands. These conversion technologies can be directly linked to individual companies or first be connected to a local energy network with storage facilities, supplying a number of companies. The local network, as well as individual companies, can exchange energy with the regional electric grid or district heating network.

\begin{tabular}{|c|c|c|c|c|c|c|c|}
\hline \multirow[b]{2}{*}{$\begin{array}{l}\text { Energy sources } \\
\begin{array}{|l}\text { - } \text { sun } \\
\text { - wind } \\
\text { - ground heat } \\
\text { - biomass } \\
\text { - biofuel } \\
\text { - hydrogen } \\
\text { - fossil fuel } \\
\text { - organic waste } \\
\text { - waste heat } \\
\text { - }\end{array}\end{array}$} & \multirow[b]{2}{*}{$\stackrel{\Leftrightarrow}{\rightleftarrows}$} & \multicolumn{2}{|c|}{ Conversion technologies } & \multicolumn{2}{|c|}{ Local networks \& storage } & \multicolumn{2}{|l|}{ Energy services } \\
\hline & & $\begin{array}{l}\text { - } \text { solar photovoltaic } \\
\text { - } \text { solar thermal } \\
\text { - } \text { wind turbine } \\
\text { - heat pump } \\
\text { - CHP } \\
\text { - fuel cell } \\
\text { - boiler } \\
\text { - gasifier } \\
\text { - } \text { organic Rankine } \\
\text { cycle } \\
\text { - } . .\end{array}$ & $\begin{array}{l}\stackrel{\Longleftrightarrow}{\rightleftarrows} \\
\stackrel{\rightleftarrows}{\rightleftarrows}\end{array}$ & 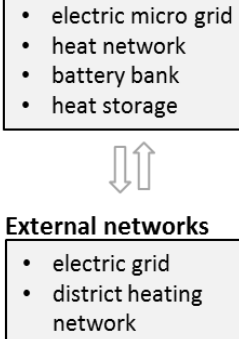 & $\stackrel{\rightleftarrows}{\rightleftarrows}$ & $\begin{array}{l}\text { Production } \\
\text { - compressed air } \\
\text { - pumps } \\
\text { - technical tools } \\
\text { - mechanical drive } \\
\text { - process steam } \\
\text { - process heating } \\
\text { - process cooling } \\
\text { - refrigeration }\end{array}$ & $\begin{array}{l}\text { Building use } \\
\text { - lighting } \\
\text { - ventilation } \\
\text { - bureautica } \\
\text { - electrical appliances } \\
\text { - space heating } \\
\text { - space cooling } \\
\text { - sanitary warm water } \\
\text { Company A }\end{array}$ \\
\hline & & & & $\stackrel{\rightleftarrows}{\rightleftarrows}$ & & & Company B \\
\hline & & & & $\Rightarrow$ & & & Company C \\
\hline
\end{tabular}

Fig. 1: Energy system superstructure

\subsection{Energy consumption profile}

The overall energy consumption profile of the business park consists of the composition of the energy profiles of the individual companies. A company's annual energy consumption profile is fully known when the annual consumption of each energy carrier (electricity, heat, fuels) is allocated to the different energy services within the company (see Fig. 2). Energy services are related either to the usage and occupancy of the buildings or to the industrial production itself. Inter-annual detail is achieved by assigning time profiles to each energy service or on a more aggregate level, to the consumption of each energy carrier (e.g. as a yearly distribution of hourly values or by disaggregating parameter values on inter-annual time slice level). Inter-annual variations of noncontrollable renewable energy production technologies, depend on climatic conditions. Energy service time profiles may depend on both climatic conditions and company or process operating schedules. The thermodynamic signature of a company's energy profile is obtained by assigning temperature levels to all thermal heat loads.

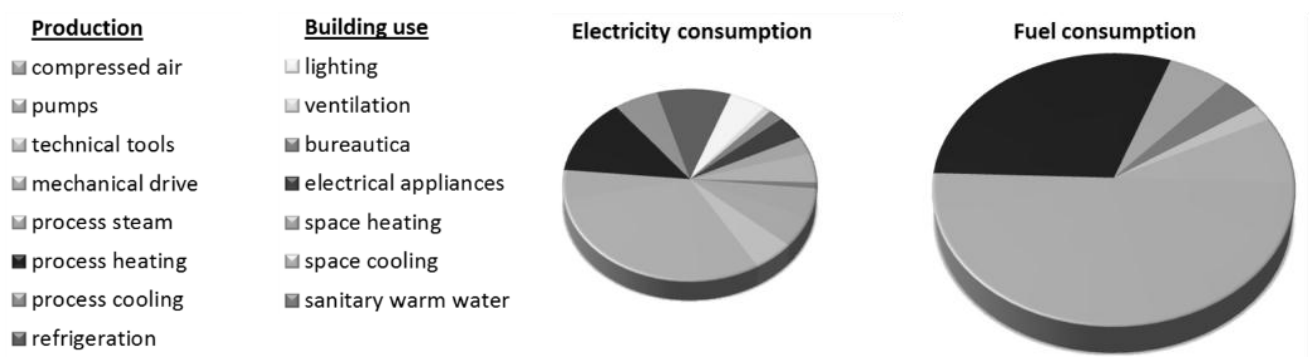

Fig. 2: Allocation of annual consumption energy carriers to energy service on company level

\subsection{System design}

The design of an energy system exists in finding a configuration of energy production technologies that satisfies demands, while attaining one or more, possibly conflicting targets. Depending on the target and on the external conditions under which it has to be achieved, the optimal system configuration will alter. A variety of targets can be envisioned, taking the form of minimisation, maximisation, limitation or minimum thresholds. Examples of variables that could be subjected to limitation or minimisation are: total energy volume exchanged 
with external networks, import costs or total discounted system costs, total carbon emissions, thermodynamic quality loss, fossil fuel consumption, etc. Maximisation or minimum thresholds could be targeted for profits on individual generator or system level, the share of renewable energy production or consumption, etc. Moreover, the system designer has to take into account the techno-economic and environmental characteristics of all system components, the inter-annual variations (time profiles) of uncontrollable renewable energy technologies and energy service demands, the dispatch strategies of energy generators, as well as the temperature levels of heat producing technologies and thermal demands. For this complex task the holistic approach provided by techno-economic energy models is indispensable.

\subsection{Energy system modelling}

A techno-economic energy model is a mathematical representation of an energy system, describing its configuration and the technologic and economic characteristics of its components. Interactions between the components vary over time, as they depend on time profiles of non-controllable renewable energy, generator dispatch strategies, and inter-annual variations or operating schedules of energy services. Techno-economic energy models can be applied to calculate the optimal configuration and operation of an energy system in terms of energy efficiency, costs or environmental impacts, and to analyse past or to predict future behaviour of a system. The different types of techno-economic energy models and their features are the subject of the following paragraphs.

\section{Classification and selection of energy models}

During the last decades a variety of techno-economic energy models has been developed, each serving particular purposes. Van Beeck proposed a classification scheme, in the process of identifying suitable models for local energy planning in developing countries, differentiating energy models according to characteristics in ten dimensions [3]. Also Nakata adopted the same categorisation [4]. Connolly et al. [5], however, established a more concise classification of energy tools by means of a survey sent out to tool developers, and presented it as a guide to identify a suitable tool for analysing the integration of renewable energy technologies. This classification distinguishes seven tool types, including simulation, scenario, equilibrium, top-down, bottom-up, operation optimisation and investment optimisation tools. Throughout literature, model, tool, modelling framework and model generator are used interchangeably. However, in a strict sense, an energy model is a simplified representation of a specific energy system, whereas a tool, modelling framework or model generator refers to the computer programme enabling the creation of various models.

From van Beeck's classification, appropriate features for modelling an industrial park's energy system are identified. Firstly, the search for an optimal future energy system, requires a scenario analysis or backcasting perspective. Secondly, an integrated approach, focusing simultaneously on technical configuration, environmental impact and comparison of different options, is called for. As a local energy system does not influence overall economy, and due to the need for flexible manipulation of the model, exogenous parameter specification is required. Also, energy supply and demand should be disaggregated, with a high level of technological detail, in order to differentiate between technologies, requiring a bottom-up approach. Furthermore, partial equilibrium, simulation and optimisation, as well as spread sheet methods are applicable. Translated to Connolly's classification, the model needs to follow a bottom-up approach, that can be applied for either simulation or scenario analysis and needs to enable optimisation of technology investment and/or operation. Taking into account these considerations, a preliminary selection of freely available models is made from Connolly's and Nakata's review, supplemented with additional models. Subsequently, a practical categorisation of energy system (ES) models is proposed, distinguishing types according to primary focus, namely ES evolution, optimisation, simulation, accounting and integration models, which are described in the following paragraphs. 


\section{$4 \quad$ Energy system evolution models}

Energy system evolution models analyse the long term evolution of an energy system, driven by technoeconomic optimisation, at international to municipal level. Numerous modelling frameworks carry this label, such as MARKAL [6], TIMES [7], ETEM [8], and OSeMOSYS [9]. These models can be used for exploring the leastcost investment paths under different scenarios that reflect alternative future visions and policies, or for developing policies to achieve a desired future (backcasting). In this context, future visions include assumptions about increase in energy demand, availability and costs of energy resources, technology efficiency and innovation, whereas energy-environmental policies decide on taxes, subsidies, exclusion of technologies, etc.

The time horizon consists of a number of periods, containing an equal or varying number of years, that are subdivided into time slices to capture inter-annual variations. Parameters and variables are disaggregated and specified accordingly, but values do not vary beyond time slice level. Time slices are defined either on an equal, or on descending hierarchic levels, such as season, weekday/weekend, day/night up to diurnal divisions. Starting from the base year, the model endogenously develops the configuration and regulates the operation of the energy system over the entire time horizon, in order to satisfy energy service demands at minimum costs, while complying with technologic, economic and environmental limits.

Therefore, an optimisation algorithm is employed, that in every time slice computes the values of the decision variables for which an objective function is minimised, subject to a number of constraints. Decision variables are the choices to be made by the model, being investments in and operation levels of technologies and import/export of commodities. The objective function represents total discounted costs to be minimised or, equivalently, net total surplus to be maximised. Indeed, for models that take into account demand priceelasticity and assume competitive markets for all commodities, supply-demand equilibrium corresponds to maximisation of net total surplus. When demands are inelastic, however, equilibrium translates into minimisation of total discounted costs [7]. These are obtained by accumulating the net present values of all costs related to technologies (investment, dismantling, operation and maintenance (O\&M), salvage), and commodities (import, export, delivery, taxes), over all time segments. Either a global or technology-specific discount rates can be applied. Optimisation constraints are given by mathematical formulations that discount and accumulate costs, model the operation of technologies, keep track of capacity extension, describe commodity balances and impose bounds to decision variables. Commodity balances ensure that the supply of a specific commodity is equal to or greater than the demand for it. Bounds can be used to introduce a minimum share of renewables, phase out existing technologies, impose a gradually decreasing carbon emission cap, etc. The optimisation assumes perfect foresight implicating full inter-temporal knowledge of future policy and economic developments over the entire planning horizon. In case objective function and equations are linear, linear programming techniques can be used, but when discrete technology sizes matter, mixed integer linear programming is required. MARKAL and TIMES are conceptualised with the General Algebraic Modelling System (GAMS) [10], whereas ETEM and OSeMOSYS are composed with the GNU Linear Programming Kit (GLPK) [11]

The overall superstructure of the energy model, also referred to as the Reference Energy System (RES), consists of a number of 'processes' that are interlinked by in- and outflows of commodities. Processes represent existing or future technologies for extraction, production, conversion, storage or use of various energy forms, whereas commodities represent energy carriers, energy services, materials or emissions. Various technologic, environmental and economic characteristics specify the behaviour of these components. Some models (ETEM, OSeMOSYS) wield a single generic sub-model for all technologies, while other models (MARKAL, TIMES) utilise one generic sub-model per technology subset. Furthermore, the base year RES configuration is calibrated to a well-documented historic year, while subsequent future configurations are determined by the model. In most ES evolution models, energy service demands are allocated to economic sectors, such as the residential, public, service, transport and industry sector. Some models (ETEM, OSeMOSYS) can only handle price-inelastic demands which, as a consequence, have to be specified for each scenario. Other models however (MARKAL, TIMES), do take into account price-elasticity. In this case, the demand in the reference scenario has to be fully 
specified, while in alternate scenarios, it is calculated endogenously, without intervention, starting from userdefined elasticities.

\subsection{MARKAL}

The MARKAL model generator has been developed by the International Energy Agency under the auspices of the Energy Technology Systems Analysis Program (IEA-ETSAP), in order to facilitate exploration of possible energy futures [6]. It has been widely applied for energy system modelling on global to community level. As an example, the MARKAL framework has been employed to replicate the UK energy system [12]. This model was later extended with flexible time slice definition to better capture peaks in electricity demand and renewable energy sources [13]. Turning to municipal level, a MARKAL instance has been set up to study the integration of renewable energy in the residential, commercial and service sectors of an Italian town (Cosmi, Macchiato et al. 2003).

\subsection{TIMES}

TIMES has been developed by IEA-ETSAP as a successor of the MARKAL framework and includes enhanced features [7]. In contrast to MARKAL, where only electricity and low-temperature heat can be disaggregated into a fixed number of rigid time slices, TIMES allows to disaggregate any commodity into any number of userdefined time slices (flexible time slicing). Moreover, input data are specified independently from the definition of time periods, which allows to easily modify the time horizon. Time-dependant data are allocated to years and the model matches these data to the periods, intra- or extrapolating where necessary. Also, processes can be vintaged, meaning that properties may be dependant of installation date of new capacity and age of a technology. Furthermore, the storage feature has been elaborated, as TIMES allows commodities to be stored in one time slice and discharged in another, whereas MARKAL only supports night-to-day-storage. STEM-E is an single-region instance of the TIMES framework covering the entire Swiss electricity system and the interconnection with neighbouring countries $[14,15]$. Its aim was to analyse the long-term development of the national electricity system and to explore TIMES' suitability as an electricity dispatch model. Also for the Belgium energy system the TIMES framework has been employed, in order to identify and explore pathways towards a 100\% renewable energy [16]. On community level, TIMES has been applied to evaluate local energy policies for the town of Pesaro [17].

\subsection{OSeMOSYS}

OSeMOSYS is an open and compact modelling framework, developed by a coalition of organisations including SEI, the International Atomic Energy Agency (IAEA), the UK Energy Research Center, and the Royal Technical University $(\mathrm{KTH})$ in Sweden [9]. In contrast to the other ES evolution models, the time horizon consists of a series of single-year, instead of multi-year, periods. The programming code has been further elaborated and modified in order to incorporate key elements inherent to smart grids, such as prioritising of demands, demand shifting and storage [18]. Economic optimisation of the mix between these elements has been exemplified for a local urban energy system. These model enhancements required time slice division to be automatically converted into a series of sequential time segments. This has been solved by labelling consecutive time segments by season, day-type and time of day in which they occur. Data specified at time slice level are then converted to time segment level and vice versa by means of conversion factors. Next to standard demand, which has to be satisfied at every moment, also flexible demand types are introduced, which can be shifted over a certain timespan within one day or partly remain unmet. The amount of unmet demand, or the time over which a quantity of demand is shifted, correspond to costs, which are integrated in the objective function. Storage levels are tracked throughout the year by accumulating net charges over preceding consecutive time intervals. In order to keep the storage level between minimum and maximum limits, new storage capacity can be invested in. 


\subsection{ETEM}

ETEM is derived from the MARKAL/TIMES framework and is tailored for urban energy systems by the ORDECSYS company. It has been elaborated for the canton of Geneva in Switzerland [8]. Recently, it has been integrated in the Luxembourg Energy-Air Quality model (LEAQ) at CRP Henri Tudor [19].

\section{$5 \quad$ Energy system optimisation models}

Energy system optimisation models wield a similar methodology as ES evolution models to calculate the least cost configuration and operation, but the time horizon is limited to a single representative year or time span, subdivided into time slices. All technology investments are made at the start and the optimised system configuration does not change over time. Optimal configurations corresponding to multiple scenarios can be compared in terms of techno-economic and environmental performance. Analogue to ES evolution models, a generic technology description is employed.

\subsection{Energy modelling framework by Voll}

At Aachen University, Voll et al. [20] developed a modelling framework for automated superstructure generation and optimisation of distributed energy supply systems, written in GAMS [10]. In order to represent annual variations in energy service demands, the representative year can be subdivided into user-defined time slices. At the relatively small scale of local distributed energy systems, the techno-economic characteristics of individual technology units play an important role. Therefore, part-load efficiency and size-dependent investment costs need to be taken into account. As a consequence, also configurations with multiple redundant units of the same technology need to be included in the solution space. This could be done by incorporating a sufficient number of units of each technology in the Reference Energy System. However, this a priori construction of possibly very large superstructures is circumvented with the automated superstructurefree synthesis and optimisation method developed by Voll et all. [20].

Voll's methodology first employs an algorithm for maximal superstructure generation to create all feasible combinations containing only one unit per technology type. Subsequently this initial superstructure is expanded by one redundant unit per technology and topographic constraints are included. Next, an optimisation algorithm calculates the configuration within the superstructure at hand and the dispatch of technology units in every time slice, that yield the minimum net-present value (or maximum when net present value is negative). Then, in a successive approach, the superstructure is continuously expanded and system configuration and operation are optimised, until the global optimal solution is found. The mathematical implementation of this method is based on a connectivity matrix that interconnects technologies and energy services. Multiple redundant units and topographic constraints are incorporated by matrix manipulations. Technologies are represented in the RES by a generic sub-model, existing of nominal efficiency, one or more part-load efficiency performance curves and an investment cost function. Functions are piecewise linearised and part-load behaviour is assumed to be independent of equipment size. However, to simulate the sizedependant nominal electric and thermal efficiencies for CHP installations, three complementary capacity ranges are incorporated.

\section{Energy system simulation models}

ES simulation models simulate the operation of an energy system within a user-defined configuration that is fixed over time. These models are used to compare alternative system configurations and to evaluate different operation strategies in terms of energetic, economic and environmental performance. Operation is simulated over a one year timespan, divided into chronologic time steps of one hour or less. Accordingly, yearly distributions of renewable energy production and energy demand are modelled either by imported measured hourly data, or by artificially created hourly time series that replicate stochastic character. The models EnergyPLAN and Homer correspond to this label. 


\subsection{EnergyPLAN}

EnergyPLAN has been developed since 1999 at Aalborg University, Denmark, to assist in techno-economic analysis of regional and national energy systems. Meanwhile, it has been widely applied in Europe to analyse the integration of renewable energy technologies. A detailed technical model description can be found in [21], while a guide for the practical use of EnergyPLAN, including the collection of relevant data can be found in [22].

EnergyPLAN is a deterministic input/output model that computes hourly energy balances for district heating and cooling, electricity, hydrogen and natural gas, within a user-defined system layout, subject to a userselected dispatch strategy. In the technical optimisation strategy, technologies are dispatched to satisfy demand, disregarding cost data, which allows the model to be run without any input of costs. Moreover, fossil fuel consumption is minimised by applying predefined priority sequences in dispatching. Within this strategy, the user can choose to operate heat producing units solely according to heat demand, or to balance both electricity and heat demands by replacing CHP with electric boilers or heat pumps and using thermal storage. Secondly, in the market optimisation strategy, the operation costs of the system are minimised under the assumption that each production unit operates to maximise its profits. Furthermore, a regulation strategy to reduce electricity production in excess of the transmission line capacity can be activated.

Model results are electricity production or consumption per technology, and electricity import or export, including related costs and revenues, at hourly level. Also hourly heat production and storage per technology is retrieved. From the energy balances, fuel consumption, $\mathrm{CO}_{2}$ emissions, and fuel, investment and operation costs are derived on an annual basis. The model's Reference Energy System is completely predefined and comprises various types of, conversion and storage technologies, fuels and energy demands, together with all possible interconnections. By specifying the technologic characteristics of these components, a particular system configuration is built up. Technologies are represented in high detail by means of complex sub-models. Energy demands are allocated to energy services and next to standard electricity demand, also three types of flexible electricity demand can be defined.

\subsection{HOMER}

HOMER is developed by the U.S. National Renewable Energy Laboratory (NREL) and is commercially available since 2009 [23]. The model facilitates the design of grid-connected and off-grid small scale energy systems by ranking all possible configurations, according to increasing discounted costs. HOMER simulates a one-year sequence of time steps of user-defined length, ranging from several hours to one minute. Within a userspecified search space, consisting of technology-specific capacity or quantity ranges, the model assembles all possible configurations. Then, for each configuration, energy balances are calculated in every simulation time step, subject to a dispatch strategy. Subsequently, infeasible configurations are omitted and feasible options are ranked by total discounted system costs over the project lifetime. Configurations are only feasible when they comply with the constraints imposed by the user, such as overall emission limits or imposed share of renewables.

When renewable technologies are insufficient to satisfy electric and thermal loads or operating reserve, controllable power sources are operated according to the 'load following' or the 'cycle charging' strategy. Under the load following strategy, when activated, a generator produces no more than required to satisfy the primary load. Consequently, the storage (battery bank) is charged only with excess renewable power. However, under the cycle charging strategy, an activated generator runs as close as possible to full capacity without generating excess electricity, while power in surplus of the primary load is used to charge the battery bank. Homer calculates the system for both strategies as the least-cost option is not known a priori. Furthermore, load priority rules decide how the produced electricity is allocated to primary load, deferrable load, battery, grid and electrolyser [24]. 
HOMER's Reference Energy System contains various predefined energy production, conversion and storage technologies, renewable resources, fuels, one thermal demand, and one deferrable and two primary electric demands. A particular system configuration is built up by selecting the components, and specifying their economic, technologic and environmental characteristics. Each technology is modelled in high detail by specific sub-models. For generators, they include nonlinear technology efficiency curves, linear cost curves and operation schedules.

\section{$7 \quad$ Energy system accounting models}

Energy system accounting models are used to quickly assess the energy requirements, costs, environmental impacts and financial feasibility of a proposed energy system in comparison to a reference case. System configurations in both proposed and reference case are user-defined and remain unchanged over time. Simplified system operation is simulated in a representative year, divided into inter-annual time slices, subject to user-selected dispatch strategies. The Reference Energy System includes a database of various separate technology sub-models. Of the studied models, only RETScreen applies for this model category.

\subsection{RETScreen}

RETSCREEN is a spreadsheet-based energy modelling tool that has been developed by the Canadian Department of Natural Resources to facilitate feasibility and prefeasibility studies for small scale renewable energy systems [25]. The model enables the comparison between a proposed renewable energy project and a conventional base case system in terms of energy efficiency, greenhouse gas emissions, life cycle costs and financial viability. A variety of project types can be analysed, such as the implementation of energy efficiency measures, power, heating or cooling projects or any combination of the latter three. The modelling period stretches over one year, subdivided into monthly time slices. In each time step, RETScreen calculates the energy balances for electricity, heating and cooling, taking into account user-defined operating strategies. Cogeneration units can be operated at full capacity or follow heat or power load, depending on the chosen dispatch strategy [26]. To meet the average monthly and peak loads for heating, cooling or power demands, first base, then intermediate, and finally peak load systems are deployed, while the fraction of total demand met by each system depends on its respective size. Simultaneously, cost analysis is performed and represented in a cumulative cashflow graph over the project life time. Furthermore, emission analysis quantifies the annual greenhouse gas emissions for both base case and proposed case. Finally, a financial analysis is performed, yielding financial indicators that enable the evaluation of the project viability. Dependent on the chosen project type, various technology types are predefined in the model's Reference Energy System. The actual configurations of both base case and proposed case energy systems are exogenously built up by specifying capacities and efficiencies. Moreover, assessment of the potential of renewable energy sources and the composition of space heating and cooling demands are aided by an integrated climate database and userdefined operating schedules.

\section{Energy system integration models}

Energy system integration models facilitate the optimal design of complex thermal energy systems, such as industrial processes, industrial plants and heat networks. They employ Pinch analysis (Linhoff 1998) to minimise energy requirements by heat exchange between process streams, and facilitate the integration of appropriate energy conversion technologies. The methodology followed by energy system integration models comprises different steps, though elaboration differs between the studied models. In a first step, after assembling the process flow model, thermodynamic calculation is performed and for each process stream the required heating or cooling load in function of temperature is computed. Secondly, from the composite curves of these cold and hot streams, the maximum heat recovery, and consequently the minimum external energy requirements, are determined, taking into account a minimum temperature difference for heat transfer. Moreover, starting from the grand composite curve, energy saving process modifications can be identified. In a third step, appropriate energy conversion technologies are selected and integrated into the heat cascade. This can be done manually by the analyst or by means of an optimisation algorithm that selects utility units from a 
technology database and optimises their operation levels in such a way that minimum energy requirements are satisfied at minimum annual costs. In a final step, the heat exchanger network, that physically enables the exchange of heat between hot and cold streams of both processes and utilities, is designed and optimised.

\subsection{EINSTEIN}

Einstein combines an energy system integration model with a guide for thermal energy audits [27, 28]. It has been developed in the European IEE project Einstein II, to optimise thermal energy supply in companies, tertiary buildings and district heating or cooling networks. The model compares the existing thermal energy supply system with a proposed alternative, which includes an optimised heat exchanger network. Simulation is carried out in hourly time steps over a one-year time horizon. The mathematical equations describing the energy system are solved iteratively, to cope with feedback loops, and dispatch strategies are approximated by a priority sequence. The Reference Energy System includes energy production, distribution and storage technologies and a heat recovery system, as well as the processes or energy services that require thermal energy. Thermal processes are modelled by means of a generic sub-model, in which a circulating fluid and a thermal reservoir are heated by external sources or by internal heat recovery.

The model is organised in different interacting modules that correspond to the steps described in 8. However, the selection of utility units has to be done manually instead of by a cost optimisation algorithm. In a first module, the existing system layout is configured within the RES, by specifying the characteristics of the thermal processes, the heat supply system and the existing heat recovery system. Based thereon, thermodynamic calculation is performed and for each process stream the required heating or cooling load in function of temperature is determined. A second module identifies optimisation measures for processes and equipment, from an extensive database. Subsequent modules make a preliminary optimised design of a heat exchanger network, taking into account the process time schedules, and assist the user in the manual selection and design of appropriate energy supply technologies. In a final module, the existing and the proposed energy system, including the optimised heat exchanger network, are compared in terms of economic and environmental performance. As economic performance indicators, net present value over the system's lifetime and payback time are wielded.

\subsection{OSMOSE}

OSMOSE is a software tool, developed by the Industrial Energy Systems Laboratory at the Swiss Federal Institute of Technology Lausanne (EPFL), for analysis and design of complex energy systems [29]. It interconnects several models, that correspond to the stepwise ES integration methodology, and steers computation sequence and data exchange.

A first model assists in assembling the processes and performs thermodynamic calculation. The second model applies Pinch analysis and optimally integrates utility units. Therefore it employs an optimisation algorithm that selects utility units from a technology database and optimises their operation levels in such a way that minimum energy requirements are satisfied at minimum annual costs. In the technology database, energy production technologies are represented by separate complex sub-models. Finally, a third model evaluates the energetic, economic and environmental performance of the energy system. In case multiple performance indicators have to be optimised, a multi-objective optimisation algorithm is activated. When multiple conflicting objectives are involved, such as the minimisation of both annual costs and emissions, a multiobjective optimisation algorithm must be used [30]. Furthermore, when using multiple inter-annual time steps, utility units have to be integrated in every time step, in such a way that annual costs are minimised [31]. In case some process streams are excluded from direct heat exchange, intermediate heat transfer units can be introduced [32]. Up to this moment, OSMOSE does not include the design and optimisation of a heat exchanger network. The methodology used by OSMOSE can be applied for the optimisation of one or more processes in an industrial plant or for the preliminary design of thermal energy networks between industrial processes at 
industrial sites or clusters [32,33]. Other applications are the optimisation of the layout and the energy supply system of district energy systems [34], and the design of energy conversion systems in urban areas [35].

\section{Hybrid models}

Hybrid models integrate features of several model types and cannot be put into one category. LEAP combines the long-term approach and time slice division of ES-evolution models with the accounting calculations of ES accounting models and the operation simulation of ES simulation models. In addition, it can be inter-linked with an ES evolution model.

\subsection{LEAP}

The energy modelling framework LEAP has been developed at the Stockholm Environment Institute (SEI), USA, to facilitate long-term energy-environment policy analysis from urban to national level [36]. Alternative scenarios, reflecting different future policies or visions can be easily constructed and compared. The model is able to encompass all sectors of an economy from resource extraction and transformation to energy consumption.

LEAP's time horizon consists of an unlimited series of subsequent years, which can be split into time slices. Due to this inter-annual subdivision, yearly shapes can be constructed to reflect the variation of various variables, such as the maximum availability of technologies. Variations in electricity demand can be introduced by allocating a yearly load shape to the entire electricity generation sector, or alternatively, by allocating energy or power load shapes to individual electric demand devices. Consequently, the electricity generation dispatch can be analysed and controlled on inter-annual level. However, also other energy demands than electricity could be time sliced. Scenarios created within LEAP correspond to different energy-environment policies or economic, technologic and demographic development assumptions over the time horizon, that influence energy demand and supply. The model compares these scenarios in terms of primary energy consumption, (social) costs and emissions. Prior to scenario analysis, the model is calibrated to a base year.

LEAP's Reference Energy System is organised in a hierarchical tree structure with separate branches for energy demand, energy transformation and energy resources. The energy transformation branch is subdivided into energy subsector modules that contain processes representing individual or average technologies or technology groups. Each process converts feedstock fuels and auxiliary fuels into the output fuels of the module to which it belongs. Branches, modules, processes and fuels are incorporated in the RES with generic sub-models that can be easily customised by the user. A specific system configuration is set up by adding components to the RES and specifying their characteristics. At technology level, input fuels, capacity, capacity factor, efficiency, availability, investment and O\&M costs, emission factors, etc. are specified by the user.

In the same LEAP analysis, different methodologies can be combined. On the demand side, bottom-up, end-use accounting as well as top-down macroeconomic techniques, can be applied to project future energy demands. On the supply side, either standard simulation or optimisation methods can be employed to calculate the capacity expansion and dispatch of technologies in the energy transformation sector, needed to meet energy demands in every time slice. In both strategies, exogenous capacity can be specified by the user to represent existing capacity as well as planned capacity additions or retirements over the time horizon. In standard simulation mode, the model calculates the investments in extra capacity that are needed, in addition to the exogenous capacity level, to maintain a minimum planning reserve margin in each year. Endogenous capacity is added in discrete sizes and following a technology order specified by the user. In optimisation mode, on the other hand, the model calculates the least-cost capacity expansion pathway and dispatch of energy production technologies in each time slice, taking into account the exogenous capacity. Least-cost in this context refers to the minimisation of total discounted costs. The optimisation is performed by OSeMOSYS (see4.3), an ES evolution model that has been integrated in the LEAP framework. In standard simulation mode, the dispatch of energy generation technologies is subject to user-selected dispatch strategies. Some strategies dispatch technologies to meet both the power requirements specified by a cumulative annual load curve and the overall 
annual energy requirements on a module, following a merit order or the ascending order of running cost. Other strategies force technologies to run at full capacity, to meet a specified fraction of the module's energy requirement, or to operate in proportion to their available capacity in each time slice. Energy demands are inelastic and are defined either directly, or as the multiplication of activity demand and energy intensity of that activity. Costs are calculated within a user-specified costing boundary and include investment and O\&M costs related to technologies, fuel import costs and export revenues, and costs of primary resource extraction.

\section{Comparison model features}

Based on the description of the studied energy models in previous paragraphs, important model features are identified and compared (see Table 1). In the following paragraphs, these characteristics are discussed in more detail.

\begin{tabular}{|c|c|c|c|c|c|c|c|}
\hline Model Type & ES evolution & ES optimisation & ES simulation & & ES accounting & ES integration & \\
\hline Model names & $\begin{array}{l}\text { ETEM, OSeMOSYS, } \\
\text { TIMES, MARKAL }\end{array}$ & Voll & EnergyPLAN & Homer & RETScreen & EINSTEIN & OSMOSE \\
\hline Focus & $\begin{array}{l}\text { least-cost investment } \\
\text { path }\end{array}$ & least-cost configuration & $\begin{array}{l}\text { configuration \& operation } \\
\text { analysis }\end{array}$ & $\begin{array}{l}\text { configuration \& operation } \\
\text { analysis }\end{array}$ & feasibility study & energy integration & $\begin{array}{l}\text { least-cost configuration } \\
\text { energy integration }\end{array}$ \\
\hline Time horizon & multi-year periods & representative year & representative year & representative year & representative year & representative year & representative year \\
\hline Temporal detail & time slices & time slices & $1 \mathrm{~h}$ time steps & $\leq 1 \mathrm{~h}$ time steps & monthly time slices & 1h time steps & time slices \\
\hline Methodology & $\begin{array}{l}\text { optimisation investment } \\
\text { \& operation }\end{array}$ & $\begin{array}{l}\text { optimisation } \\
\text { configuration \& operation }\end{array}$ & $\begin{array}{l}\text { performance calculation } \\
\text { specified system } \\
\text { dispatch strategy }\end{array}$ & $\begin{array}{l}\text { performance calculation } \\
\text { specified system } \\
\text { dispatch strategy }\end{array}$ & $\begin{array}{l}\text { performance calculation } \\
\text { specified system } \\
\text { dispatch strategy }\end{array}$ & $\begin{array}{l}\text { performance calculation } \\
\text { specified system } \\
\text { dispatch strategy }\end{array}$ & $\begin{array}{l}\text { (multi-obj.) optimisation } \\
\text { configuration \& operation }\end{array}$ \\
\hline $\begin{array}{l}\text { Comparative } \\
\text { analysis }\end{array}$ & scenarios & scenarios & configurations & configurations & configurations & configurations & scenarios \\
\hline RES configuration & $\begin{array}{l}\text { endogenous } \\
\text { evolves over time } \\
\text { generic technology } \\
\text { model } \\
\text { extendable }\end{array}$ & $\begin{array}{l}\text { endogenous } \\
\text { fixed in time } \\
\text { generic technology } \\
\text { model } \\
\text { extendable }\end{array}$ & $\begin{array}{l}\text { exogenous } \\
\text { fixed in time } \\
\text { specific technology } \\
\text { models } \\
\text { not extendable }\end{array}$ & $\begin{array}{l}\text { exogenous endogenous } \\
\text { combinations } \\
\text { fixed in time } \\
\text { specific technology } \\
\text { models } \\
\text { not extendable }\end{array}$ & $\begin{array}{l}\text { exogenous } \\
\text { fixed in time } \\
\text { specific technology } \\
\text { models } \\
\text { not extendable }\end{array}$ & $\begin{array}{l}\text { exogenous } \\
\text { fixed in time } \\
\text { specific technology } \\
\text { models } \\
\text { not extendable }\end{array}$ & $\begin{array}{l}\text { endogenous } \\
\text { fixed in time } \\
\text { specific technology } \\
\text { models } \\
\text { extendable }\end{array}$ \\
\hline Demand & $\begin{array}{l}\text { energy services } \\
\text { electricity, heat, fuel } \\
\text { elastic / inelastic }\end{array}$ & $\begin{array}{l}\text { energy services } \\
\text { electricity, heat, fuel } \\
\text { inelastic }\end{array}$ & $\begin{array}{l}\text { electricity, heat, fuel } \\
\text { allocated to energy } \\
\text { services } \\
\text { electricity elastic }\end{array}$ & $\begin{array}{l}\text { electricity, heat, overall } \\
\text { demand } \\
\text { inelastic }\end{array}$ & $\begin{array}{l}\text { space heating \& cooling, } \\
\text { hot water } \\
\text { electricity } \\
\text { inelastic }\end{array}$ & $\begin{array}{l}\text { electricity, heat, fuel } \\
\text { thermal processes, } \\
\text { buildings } \\
\text { inelastic }\end{array}$ & $\begin{array}{l}\text { energy services } \\
\text { electricity, heat, fuel } \\
\text { for process units } \\
\text { inelastic }\end{array}$ \\
\hline $\begin{array}{l}\text { Heat } \\
\text { representation }\end{array}$ & commodity & commodity & commodity & commodity & commodity & heat-temperature & heat-temperature \\
\hline Application scale & global to municipal & project, site, district & national to municipal & project & project & industrial plant & $\begin{array}{l}\text { industrial plant, site, } \\
\text { district }\end{array}$ \\
\hline
\end{tabular}

Table 1: Comparison features techno-economic models

\subsection{Focus}

ES evolution models are used to construct and analyse least cost investment paths towards a desired long-term future, taking into account changing external conditions. ES optimisation models, however, calculate the leastcost configuration for a representative year. ES simulation models are used to compare different configurations and to evaluate different operation strategies. ES accounting models are employed to assess the financial feasibility of proposed configurations, while comparing them with a reference case. ES integration models focus on optimal integration of energy conversion technologies, starting from thermal energy demands that have been minimised by heat exchange.

\subsection{Time horizon}

ES evolution models cover a time horizon, extending from base year to end year, that consists of a series of multi-year (or single-year) periods. Each period is conceived as a repetition of its representative year, and at this level the energy system data are specified. Annual and periodic costs are discounted and accumulated over the time horizon to yield total discounted costs. Other model types however, analyse techno-economic aspects only in a single representative year or timespan. As a result, they cannot model evolution of parameters and variables over subsequent years. Nevertheless, a simplified financial analysis can be performed over the project lifetime.

\subsection{Temporal detail}


Seasonal, weekly or daily variations in energy supply and demand patterns can be captured by subdividing the year into time segments. Parameters and variables are disaggregated and specified accordingly, keeping constant values at segment level. Consequently, this inter-annual subdivision should be sufficiently detailed to capture key characteristics and peaks in time profiles [15]. Time slices aggregate time intervals over the year with similar conditions and thus have no inherent chronology, whereas time steps are sequential uniform paces in time. For modelling the behaviour of storage technologies, chronologic time steps are required, although time sequence can also be extracted from time slice definition [18]. ES evolution and ES optimisation models use time slice division, that may be hierarchically organised in seasonal, weekly and diurnal levels. Also ES accounting models use time slices, in order to include e.g. monthly variations. ES simulation models on the other hand, apply hourly time steps and thus exhibit a higher temporal detail. By importing either measured or artificially created annual distributions of hourly values, these models can represent the stochastic character of renewable energy and unpredictable deviations in energy demand. In the case of ES integration models, EINSTEIN simulates hourly time steps, while time slices with OSMOSE are user-defined.

\subsection{Methodology}

ES evolution models employ an optimisation algorithm to calculate the values of the decision variables that minimise or maximise an objective function, expressing economic performance, subject to a number of constraints. When demands are inelastic, total discounted costs are minimised, whereas with elastic demands, total surplus is maximised. Decision variables are technology investments, technology operation levels and trade of commodities. Constraints are given by the equations governing the system's operation, and by bounds to decision and output variables in every time slice and/or every period. ES optimisation models follow an analogous approach, but all investments are made at the start of the representative year. The ES integration model OSMOSE first calculates minimum energy requirements and subsequently employs an optimisation algorithm to optimise selection and operation levels of energy conversion units, so that annualised costs are minimised, subject to heat and power balances and equations and bounds modelling process and utility units. When multiple conflicting objectives are involved, such as the minimisation of both costs and carbon emissions, a multi-objective optimisation algorithm is required. In contrast, ES simulation and ES accounting models start from user-defined system configurations and dispatch strategies, and directly calculate the energetic, economic and environmental performance thereof. EINSTEIN performs energy integration, starting from a user-defined system layout and employs an iterative calculation method to cope with feedback loops.

\subsection{Comparative analysis}

ES evolution models generate the least-cost technology investment path and operation, for a specific scenario. Optimal solutions for alternative scenarios can be compared to the solution for a reference scenario, in terms of energetic, economic and environmental performance. In this context, each scenario corresponds to a separate model set-up, represented by a coherent set of input parameters over the time horizon that define energy service demands, resource potentials, technology characteristics and regulatory or policy constraints. ES optimisation models and OSMOSE compute the least cost system configuration and operation in a specific scenario. Therefore, also these model types allow for comparison of alternative scenarios to a reference scenario. In this case, a scenario is defined by a parameter set describing the conditions in the representative (future) year. Other model types evaluate the performance of user-defined alternative configurations that reflect different choices and conditions in the representative year.

\subsection{Reference energy system configuration}

The Reference Energy System (RES) or superstructure describes the techno-economic behaviour of all model components (energy resources, -technologies, -carriers and-demands) and the possible interactions between them. A particular configuration is set up by selecting the components to be included and specifying their characteristics. In the case of ES evolution models, the system configuration endogenously evolves over subsequent time periods, starting from the initial configuration and following the computed optimal 
investment path. ES optimisation models and OSMOSE, compute the optimal configuration once for the representative year or time span and the configuration does not change over time. The other model types are based on user-defined configurations, which also remain unchanged over time. Yet, Homer endogenously creates a finite number of technology combinations within user-defined ranges with discrete steps. ES evolution and ES optimisation models wield a single generic sub-model for all technologies, which makes their superstructure easily extendable. However, some particular models employ one generic sub-model per technology subset. Osmose on the other hand, uses complex sub-models to represent technologies, but nonetheless, new technology sub-models can readily be added. Also ES simulation, ES accounting models and EINSTEIN include a database of specific technology sub-models, but the predefined superstructure cannot be extended by the user.

\subsection{Demand side}

In ES evolution and ES optimisation models, any type of energy service demand could be defined by the user due to the generic technology sub-model description. For energy system modelling on municipal scale and beyond, these demands are mostly allocated to residential, public, service, transport and industry sectors. For the other model types however, demand types are predefined and include electricity, heat or fuel demands, allocated to energy services, if applicable. Although, with OSMOSE, energy service demands, such as mobility could directly be included. Some ES evolution models can only handle price-inelastic demands, necessarily specified for each scenario. For price-elastic models of this type however, the demand in the reference scenario has to be fully specified, while in alternate scenarios it is calculated endogenously, based on userdefined elasticities. The other model types do not incorporate elasticity, except for EnergyPLAN, that includes price elasticity for electricity demand.

\subsection{Heat representation}

ES integration models focus on the thermal demand of process streams in function of temperature, while the other model types consider heat as a commodity that can be produced, consumed, exported or imported, without specifying the level of thermodynamic quality.

\subsection{Application scale}

ES evolution models and EnergyPLAN are typically applied to evaluate the effects of different energy policies on the development of an energy system at global to municipal scale. EINSTEIN and OSMOSE primarily focus on industrial sites, while ES accounting models and RETScreen are project-oriented. Energy system optimisation models could fall in either category.

\section{Generic technology sub-models}

ES evolution and ES optimisation models employ a generic mathematical description to represent technologies. This paragraph zooms in on the generic technology sub-models used by ETEM, OSeMOSYS and the framework of Voll et al., into further detail (see Fig. 3).

In ETEM, a technology is modelled as a process converting ingoing flows to outgoing flows, that each contain one or more commodities, with one of the outflows labelled as the process's activity. In each time slice, the maximal attainable activity level is proportional to the total available capacity of the process. Conversion from a specific inflow to a specific outflow is described by a constant efficiency. Furthermore, in every period, specific investment and fixed and variable O\&M costs are constant over the ranges of capacity addition, total installed capacity and activity respectively. Also, specific import, export and delivery costs of commodities are constant at time slice level. Although this generic technology description is not directly suited for modelling storage, Babonneau et al. introduced intra-day energy storage for electric vehicles and small gas fuel-cells with heat storage [37]. Therefore, these technologies had to be decomposed into a demand and a storage component and extra commodities for storage had to be created. 


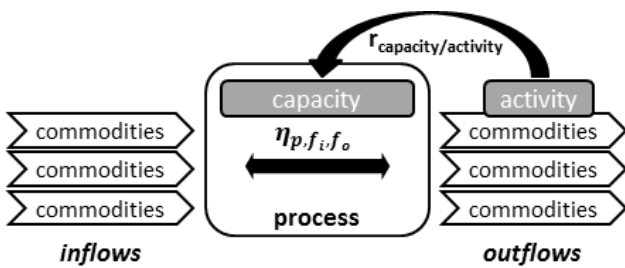

ETEM

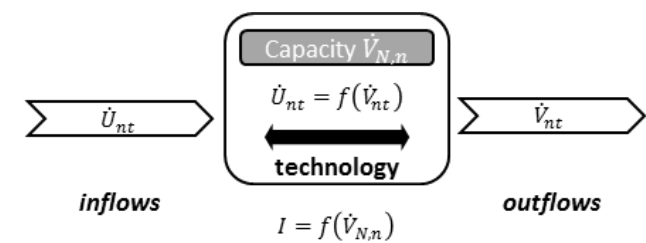

Voll

Fig. 3: Generic technology sub-models

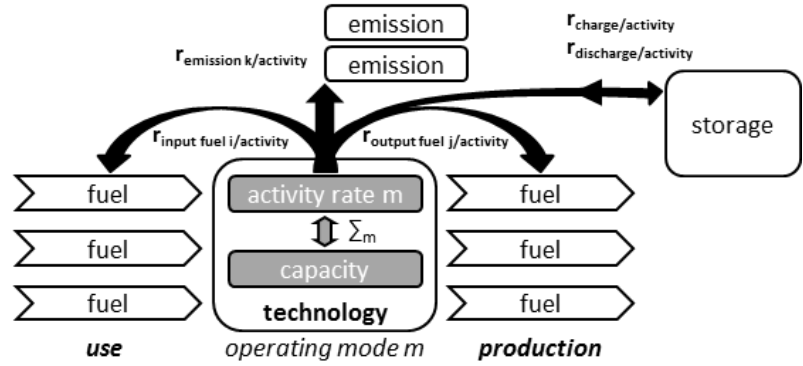

OSeMOSYS

In OSeMOSYS, all energy conversion technologies, energy imports or resource extractions in the RES are represented by a generic technology sub-model, based on two decision variables: activity rate and capacity. The total activity over all operation modes of a technology is limited by its total available capacity, on both time slice and annual level. The rates of all fuel in- and outputs and emissions are linked to the activity rate by constant ratios. Fuels may comprise energy carriers as well as energy services. Generally, a technology's activity is chosen to represent the use or production of a fuel, so the corresponding fuel-activity ratio equals 1 . Furthermore, the technology model can include different operation modes, so that for example different heat/electricity ratios in the operation of a CHP can be simulated. Analogously to ETEM, specific investment, variable operating costs and emission penalties are assumed to be constant. Fuel costs are included as variable operating costs of import or extraction technologies. A technology can charge or discharge a storage facility to which it is connected, in dedicated operation modes, at rates proportional to its activity rate. The model keeps track of the charging level of the storage facility, while keeping it between minimum and maximum boundaries, over a chronologic sequence of time steps, that is automatically derived from time slice formulation [18].

In the framework developed by Voll et al., technologies are represented in the Reference Energy System by a generic sub-model, existing of nominal efficiencies between in- and outflows, one or more part-load efficiency performance curves and an investment cost function. Functions are piecewise linearised and part-load behaviour is assumed to be independent of equipment size. However, to simulate the size-dependant nominal electric and thermal efficiencies for CHP installations, three complementary capacity ranges are incorporated.

In contrast to the Voll et al. framework, present versions of ETEM and OSeMOSYS do not take into account part-load efficiency and economy of scale, due to constant ratios defining technology efficiency and constant specific costs.

\section{Towards a techno-economic model for business park energy systems}

From the considerations in paragraphs 10 and 11, features important for modelling business park energy systems can be identified. Based thereon, an existing model framework can be modified or a new one can be developed. An optimisation approach is preferred, as it automatically calculates system configuration and operation that achieve one or more predefined targets. To simulate the time-varying interactions between energy service demands, uncontrollable renewable energy sources, local energy storage, controllable energy generators and energy import/export, sufficient temporal detail is required. Furthermore, considering the relatively small scale of business park energy systems, the model must enable the representation of (multiple) separate units per technology, instead of averaged technologies. To correctly model heat flows in energy 
generation and demand, they must be represented by heat-temperature profiles. These features are discussed more detailed in the following paragraphs.

\subsection{Sufficient inter-annual temporal detail}

Time slices aggregate time intervals, over the year, that show similar conditions in energy supply and demand (e.g. February weekday evening). As a consequence, time slice division greatly reduces the number of time segments to be analysed, in comparison to the use of sequential time steps. However, these slices should be carefully customised to capture key trends and peaks in energy service demands and renewable resource availability, in order to obtain realistic system operation. The influence of inter-annual detail has been investigated by Kannan and Turton [15]. They concluded that low temporal detail flattens peaks in energy supply and demand, and that consequently the operational constraints to base-load power plants and the need for storage or supply-demand management are underestimated. Especially, taking into account the variation between weekday and weekend appeared to be very important.

\subsection{Optimisation}

Optimisation-based models that calculate the least-cost configuration and operation of the system avoid the need for configurations proposed by the analyst. In order to facilitate the trade-off between multiple conflicting objectives, such as minimisation of both costs and carbon emissions, multi-objective optimisation methods need to be employed. In case the energy system will be built or retrofitted in several stages, or if external conditions are expected to change over a long-term time horizon, the investment path and the gradual development of the system configuration need to be optimised.

\subsection{Component-based Reference Energy System}

The model framework must cover thermal as well as electrical energy demands that are allocated to energy services. A superstructure description based on generic technology sub-models can easily be extended and enables the introduction of any energy service demand or energy production technology.

\subsection{Detail on technology unit level}

To accurately replicate the techno-economic characteristics of individual technology units within the energy system, part-load efficiency between operation limits, and size-dependent investment costs must be modelled. Consequently also configurations with multiple redundant units of the same technology belong to the solution space. An automated superstructure generation and optimisation algorithm avoids the a priori definition of the number of redundant units per technology.

\subsection{Energy storage and flexible demand}

By including storage technologies into the model framework, energy exchange with external networks to balance compensate differences between energy production and demand, can be limited. As time slice division has no inherent chronology, time sequence has to be introduced artificially. Demand-side management can be modelled by identifying, next to standard demands, also flexible demand types that can be shifted in time or partly remain unmet.

\subsection{Thermodynamic quality of heat and heat exchange restrictions}

When heat is modelled as a commodity, differences in thermodynamic quality are disregarded. A correct representation of heat flows and heat exchange can only be achieved by including the heat-temperature profiles of heat generators and demands. Energy integration is based on direct heat exchange between all or part of the process streams. However, on mixed business parks, containing a multitude of company types, direct process to process heat exchanges are not always plausible. A more realistic assumption is that heat can only be exchanged between companies through an intermediary heat transfer network, and that companies 
have already individually performed internal energy integration. This corresponds to the assumptions of total site analysis [38].

\section{Conclusions}

The grass-root or retrofit design of low carbon business park energy systems requires a holistic technoeconomic modelling approach to take into account the time-varying interactions between the system's components. In order to identify appropriate energy models, a confined review has been carried out, while detecting and comparing relevant model features. Based on common properties, a practical new typology has been proposed, existing of ES evolution, optimisation, simulation, accounting and integration models. In conclusion, important aspects that should be integrated into the energy model framework are highlighted. An appropriate model employs (multi-objective) optimisation, wields a generic technology description on equipment level, in a time horizon or representative year with customised time slice division. It automatically generates and successively expands its superstructure, and includes energy storage technologies and flexible energy demands, while heat flows are characterised by temperature-heat profiles.

\section{References}

[1] IEA. CO2 Emissions from Fuel Combustion Highlights - 2012 Edition. Paris, France: IEA, 2012.

[2] Maes T, Van Eetvelde G, De Ras E, Block C, Pisman A, Verhofstede B, et al. Energy management on industrial parks in Flanders. Renewable and Sustainable Energy Reviews. 2011;15(4):1988-2005.

[3] van Beeck N. A new decision support method for local energy planning in developing countries. Tilburg, the Netherlands: Tilburg University, 2003.

[4] Nakata T, Silva D, Rodionov M. Application of energy system models for designing a low-carbon society. Prog Energ Combust. 2011;37(4):462-502.

[5] Connolly D, Lund H, Mathiesen BV, Leahy M. A review of computer tools for analysing the integration of renewable energy into various energy systems. Applied Energy. 2010;87(4):1059-82.

[6] Loulou R, Goldstein G, Noble K. Documentation for the MARKAL Family of Models. Energy Technology Systems Analysis Programme, 2004.

[7] Loulou R, Remne U, Kanudia A, Lehtila A, Goldstein G. Documentation for the TIMES Model. Energy Technology Systems Analysis Programme, 2005.

[8] Drouet L, Thénié J. An Energy-Technology-Environment Model to Assess Urban Sustainable Development Policies: Reference Manual - Version 2.1. Chêne-Bougeries, Switzerland: ORDECSYS, 2009.

[9] Howells M, Rogner H, Strachan N, Heaps C, Huntington H, Kypreos S, et al. OSeMOSYS: The Open Source Energy Modeling System An introduction to its ethos, structure and development. Energy Policy. 2011;39(10):5850-70.

[10] Rosenthal RE. GAMS - A User's Guide. Washington, USA: GAMS Development Corporation, 2012.

[11] Makhorin A. GLPK (GNU Linear Programming Kit). Moscow: Department for Applied Informatics, Moscow Aviation Institute 2012. www.gnu.org/software/glpk.

[12] Kannan R, Strachan N, Pye S, Anandarajah G, Balta-Ozkan N. UK MARKAL Model Documentation. UK Energy Research Centre, 2007.

[13] Kannan R. The development and application of a temporal MARKAL energy system model using flexible time slicing. Applied Energy. 2011;88(6):2261-72.

[14] Kannan R, Turton H. Documentation on the Development of the Swiss TIMES Electricity Model (STEM-E). Paul Scherrer Institut, 2011.

[15] Kannan R, Turton H. A Long-Term Electricity Dispatch Model with the TIMES Framework. Environmental Modeling and Assessment. 2012:1-19.

[16] Devogelaer D, Duerinck J, Gusbin D, Marenne Y, Nijs W, Orsini M, et al. Towards $100 \%$ renewable energy in Belgium by 2050. Belgium: FPB, ICEDD, VITO, 2012.

[17] Comodi G, Cioccolanti L, Gargiulo M. Municipal scale scenario: Analysis of an Italian seaside town with MarkAL-TIMES. Energy Policy. 2012;41(0):303-15. 
[18] Welsch M, Howells M, Bazilian M, DeCarolis JF, Hermann S, Rogner HH. Modelling elements of Smart Grids - Enhancing the OSeMOSYS (Open Source Energy Modelling System) code. Energy. 2012;46(1):337-50.

[19] Zachary DS, Drouet L, Leopold U, Aleluia Reis L. Trade-offs between energy cost and health impact in a regional coupled energy-air quality model: the LEAQ model. Environmental Research Letters. 2011;6(2):024021.

[20] Voll P, Klaffke C, Hennen M, Bardow A. Automated superstructure-based synthesis and optimization of distributed energy supply systems. Energy. 2013;50(0):374-88.

[21] Lund H. EnergyPLAN Advanced Energy Systems Analysis Computer Model Documentation Version 10.0. Aalborg, Denmark: Aalborg University, 2012.

[22] Connolly D. A User's Guide to EnergyPLAN. Limerick, Ireland: University of Limerick, 2010.

[23] Homer Energy LLC. Homer. 2013. homerenergy.com. accessed 20.02.2013.

[24] Lambert T, Gilman P, Lilienthall P. Micropower system modelling with HOMER. In: Farret FA, Simões MG, editors. Integration of Alternative Sources of Energy. Hoboken, New Jersey, USA: John Wiley \& Sons Inc.; 2006. p. 408.

[25] RETScreen. Clean Energy Project Analysis: RETScreen Engineering \& Cases. Natural Resources Canada, 2005.

[26] RETScreen. Combined Heat \& Power (Cogeneration). Canada: Natural Resources Canada, 2005.

[27] Schweiger H. Guide for Einstein Thermal Energy Audits. Barcelona, Spain, Berlin, Germany: energyXperts.NET, 2011.

[28] Schweiger H, Danov S, Vannoni C, Facci E, Ries J, Bertrand A, et al. EINSTEIN Software Tool Technical Manual. 2012.

[29] Palazzi F. Osmose User Manual. Lausanne, Switzerland: Industrial Energy Systems Laboratory, Swiss Federal Institute of Technology Lausanne, 2010.

[30] Fazlollahi S, Maréchal F. Multi-objective, multi-period optimization of biomass conversion technologies using evolutionary algorithms and mixed integer linear programming (MILP). Applied Thermal Engineering. 2013;50(2):1504-13.

[31] Marechal F, Kalitventzeff B. Targeting the integration of multi-period utility systems for site scale process integration. Applied Thermal Engineering. 2003;23(14):1763-84.

[32] Becker $\mathrm{H}$, Maréchal F. Energy integration of industrial sites with heat exchange restrictions. Computers and Chemical Engineering. 2012;37(0):104-18.

[33] Nemet A, Klemeš JJ, Varbanov P, Aktins MJ, Walmsley M. Total site methodology as a tool for planning and strategic decisions. Chemical Engineering Transactions. 2012;29:115-20.

[34] Weber C, Maréchal F, Favrat D. Design and optimization of district energy systems. Computer Aided Chemical Engineering. 2007;24(0):1127-32.

[35] Gerber L. Integration of Life Cycle Assessment in the conceptual design of renewable energy conversion systems. Lausanne: Swiss Federal Institute of Technology Lausanne, 2012.

[36] Heaps C, Long-range Energy Alternatives Planning (LEAP) system, Somerville, MA, USA, 2012. www.energycommunity.org.

[37] Babonneau F, A. H, J. TG, J. T. Assessing the future of renewable and smart grid technologies in regional energy systems. Swiss journal of economics and statistics. 2012;Vol. 148.2012(2):p. 229-73.

[38] Klemeš J, Dhole VR, Raissi K, Perry SJ, Puigjaner L. Targeting and design methodology for reduction of fuel, power and CO2 on total sites. Applied Thermal Engineering. 1997;17(8-10):9931003. 